QVIPUKAMAYOC Revista de la Facultad de Ciencias Contables

Vol. 20 N. 38 pp. 59-64 (2012) UNMSM, Lima, Perú

ISSN: 1560-9103 (versión impresa) / ISSN: 1609-8196 (versión electrónica)

\title{
CARACTERÍSTICAS INGENIERILES DE LA CORRUPCIÓN, EN EL CAMPO ECONÓMICO Y FINANCIERO, Y LA EFICACIA \\ DE LAS ACCIONES DE CONTROL EN LAS ENTIDADES GUBERNAMENTALES EN EL PERÚ
}

\author{
ENGINEERING CHARACTERISTICS OF CORRUPTION IN THE \\ ECONOMIC AND FINANCIAL FIELD, AND EFFECTIVENESS OF THE \\ SHARES OF CONTROL IN GOVERNMENT INSTITUTIONS IN PERU \\ Nicko Gomero GonzÁles * \\ EDUARdo MONTES FARro** \\ Docente Principal de la Facultad de Ciencias Contables \\ Universidad Nacional Mayor de San Marcos-UNMSM \\ Lima-Perú
}

[Recepción: Setiembre de 2012/ Conformidad: Octubre 2012]

\section{RESUMEN}

La corrupción se ha encargado de ejercer presión negativa en contra el crecimiento económico, estos hechos ilegales comprometen presupuestos y gobiernos, cuyos efectos los podrían sumergir en continuos desequilibrios sociales y económicos. La corrupción no es un fenómeno local, sino a través del tiempo se ha ido perfeccionado para su globalización y en este proceso ha estado presente la tecnología, plasmada en los medios informáticos que facilitaron el actuar de aquellos que no les interesa el bien común, sino solo el objetivo personal. La corrupción ha sido la responsable de generar perdidas al gobierno peruano en promedio 14 mil millones de dólares, casi el $50 \%$ de las exportaciones, esta cifra es la mejor señal que los actos corruptos siguen presente en la sociedad y aprovechándose de las debilidades que presentan las mallas legales para su penalización. bajo este contexto, es que el artículo que se presenta persigue como objetivo explicar los efectos económicos y sociales de la corrupción y los medios de precisión que utiliza para evadir todo tipo de responsabilidades administrativas y penales.

Palabras Clave: Corrupción global, corrupción local, presupuesto público, proyectos públicos, presupuesto ejecutado, auditoria

\begin{abstract}
Corruption has been responsible for apply a negative lobbying against economic growth; these illegal acts compromise the budgets and governments, and its effects could them dip out in continuous social and economic imbalances. Corruption is not a local phenomenon, but over the time has been perfected for its globalization and in this process has been present the technology; reflected in computer media that facilitated the actions of those who are not interested in the public good, only in his personal interest. Corruption has been responsible for generating of lost for Peruvian government in an average of 14 billion dollars, almost 50\% of exports, this figure is the best sign that corrupt acts are still present in society and are continuing to exploit weaknesses that present legal meshes for its penalization. In this context, the aim of this article is to explain the economic and social effects of corruption, and the means of precision that used to avoid all kinds of administrative and criminal responsibilities.
\end{abstract}

Keywords: global corruption; local corruption, public budget, public projects, executed budget, audit.

* Doctor en Ciencias Económicas. Docente Investigador y de Postgrado-UNMSM. E-mail: nickgo_6@msn.com, gomero_econ@yahoo.es

** Egresado de Maestría en Contabilidad con mención en costos y presupuestos en la gestión estratégica-UNMSM. Contador Público Colegiado Certificado. Docente Investigador-UNMSM. Email: amontesfa@yahoo.es 


\section{MARCO TEÓRICO}

\subsection{Los efectos de la corrupción enfoque teórico}

No solo los movimientos económicos y financieros se han globalizado en el planeta. También el fenómeno de la corrupción ha traspasado las esferas locales para convertirse en una amenaza de tipo global. Sin duda, los impactos de este mega problema va más allá del campo político, por ello, ahora se viene evaluando que este fenómeno se ha convertido en un factor que podría resquebrajar los cimientos económicos mejores estructurados de un país, y así lo demuestra la última crisis financiera internacional, y otros casos, donde gobiernos, cuya doctrina de conducción del Estado estuvo basado en este principio atípico de tipo estructural, solo generaron escenarios de pobreza y atraso social.

Conceptualmente se entiende por corrupción como el aprovechamiento del poder político para condicionar comportamientos de los demás actores sociales, o también la pre condición de los escenarios económicos a lo que desean quienes poseen en forma coyuntural o permanente el poder político. Como se puede apreciar en esta argumentación conceptual, están presente dos actores sociales: Quienes poseen el poder político, a quienes se les llama gobernantes y en la otra orilla de la sociedad están lo afectados por este fenómeno atípico, a quienes se les identifica como gobernados. A la luz de este marco conceptual se puede afirmar que, lo que llegan ejercer la fuerza, que paradójicamente les conceden los gobernados, son los que se encargan de desarrollar y fortalecer la corrupción, que, como se argumentó anteriormente, muchas veces lo imponen como doctrina de gobierno.

Hasta los marcos normativos están hechos a la medida. Al final de cuentan quienes tejen las mallas legales son los que ejercen el poder, y como es obvio pensar, estos actores políticos no podrían crear mecanismos que puedan ir contra su conducta de gobierno. Todo lo contrario, la fabricación de las normas debe estar tan bien cimentados y construidas para crear así mecanismos de protección o impunidad a favor de quienes actúan al margen de los principios morales, éticos $y$ legales que deben primar en una sociedad.

Los efectos de la corrupción son por demás perniciosos para una sociedad: Pobreza, desequilibrios presupuestales, carencia de inversiones, evasión fiscal, entre otros son los resultados que se darán en el plazo mediato, como producto de estas inconductas legales, los cuales se reflejarán en los principales indicadores macroeconómicos. Es pertinente anotar que los desequilibrios no solo se pueden dar por un mal diseño e implementación de políticas públicas, sino también se pueden originar por hechos que caminan al margen de los marcos normativos, éticos y morales de una sociedad, que de imponerse como cultura de vida seria mucho mas peligroso para la sociedad.

Cabe precisar que, cuando se analizan los impactos de la corrupción, no solo debe centrarse la mirada en la magnitud del desfalco que se realizó en contra del Estado o quienes irrumpieron con malas acciones en los circuitos financieros gubernamentales y privados, sino que se debe de evaluar el trasfondo de todos estos hechos, y con ello los efectos directos y colaterales que genera este fenómeno perniciosos. Si bien la judilizacion de la corrupción implica detectar a quienes realizaron los actos de corrupción y las acciones ilegales que cometieron, tarea que también le compete a los organismos de control del Estado, pero este hecho no excluye otros impactos macro económicos, políticos y sociales que de hecho deben convertirse en los 
CARACTERÍSTICAS INGENIERILES DE LA CORRUPCIÓN, EN EL CAMPO ECONÓMICO Y FINANCIERO, Y LA EFICACIA DE LAS ACCIONES DE CONTROL EN LAS ENTIDADES GUBERNAMENTALES EN EL PERÚ

parámetros de referencias para diseñar e implementar políticas públicas que conlleven a neutralizar las acciones de corrupción en todas las esferas de una comunidad.

Como bien se sabe la corrupción no es exclusividad de los Organismos del Estado, más específicamente del aparato público, sus ramificaciones se ha ido extendiendo por todas las actividades de la sociedad, pero con mucho mayor fuerza donde los flujos financieros poseen mayor grado de potencialidad. Los hechos de corrupción inclusive han trastocado esferas donde la espiritualidad y la fe son los insumos más importantes en su estructura organizacional. Que no decir de los grupos políticos o de poder, espacios que se han visto envueltos en escándalos financieros y económicos, así lo evidencian las encuestas de opinión.

Con la cadena de la corrupción y los eslabones que va formando, cada vez hay menos espacios donde la ética, los valores, el buen ciudadano son los ingredientes principales para la convivencia humana. La cultura del respeto mutuo, la decencia personal y profesional, están siendo avasallados casi ya en forma estructural por la cultura de las conductitas atípicas de las personas. En esta última categoría encontramos aquellos individuos que no les interesa cuanto pierde la sociedad con sus proceder subterráneo, sino lo que prima es la acumulación de riqueza personal, y corporativa, sin importar cuales sean los medios que utilice para este fin.

Como toda organización, la corrupción también se ha sofisticado, por ejemplo ahora se emplean los medios cibernéticos, las encriptaciones de informaciones y de cuentas bancarias, la creación de organizaciones virtuales, acciones que poseen como plataforma de soporte a las redes tecnológicas. Como se sabe, cada país tiene su sistema de control . Hasta sus órganos de inteligencia financiera, cuya función principal es la de detectar acciones ilegales contra el Estado, pero por los resultados observados se puede argumentar que sus estrategias son poco eficientes, hasta se podría decir estériles en la lucha contra la corrupción. Sin duda la sofisticación organizativa y tecnológica de laa corrupción ha mermado la capacidad de los Órganos Gubernamentales que tienen por función eliminar en todas sus formas a los actores directos e indirectos de la corrupción, sin importar cual sea su posición jerárquica de tipo político o económico.

Ya no se puede argumentar a la corrupción como un hecho aislado, sino que se ha convertido en un fenómeno corporativo, bajo esta óptica, es que se han formado grandes organizaciones, equivalente a empresas multinacionales o transnacionales, que actúan conectados en redes organizacionales, y siempre buscando lograr el máximo lucro pero de manera ilegal. Sino hay que preguntarse de donde fluyen los grandes montos de capitales que van a parar en los paraísos financieros. Como bien lo han demostrado muchas investigaciones, una de las fuentes que dan vida a estos enclaves bancarios, es la evasión y la elusión tributaria, que inclusive proceden de países considerados del tercer mundo o extremadamente pobres. A pesar de muchas necesidades, estos países tienen que soportar las cargas políticas que erosionan las arcas financieras del Estado.

\subsection{Los fundamentos estructurales de la corrupción}

A continuación se presenta una lista de factores que sustentan los actos de corrupción en las naciones:

$\checkmark$ Pobres principios morales y éticos de la clase gobernante

$\checkmark$ Fácil aceptación de estos hechos en la po- 
blación, de esta forma aceptan estos actos como un fenómeno normal en su conducta de vida, hasta convertirse en una cultura.

$\checkmark$ Enmallado legal complejo, el cual tiene que ser afrontado por la comunidad empresarial. Para vulnerar estas trabas legales se ven forzados a ejecutar acciones que están reñidos con la moral

$\checkmark$ Concentración del poder político aunando con la permanencia de quienes la ejercen en beneficio propio

$\checkmark$ Formación de conglomerados económicos que hacen uso de la redes tecnológicas para activar hechos de carácter ilegal y que atentan la integridad de los Estados

\section{CIFRAS DE LA CORRUPCION}

Los efectos económicos de la corrupción son evidentes, para su fundamentación, en un principio se puede mencionar el estudio realizado por Robert Klitgaard, en su estudio, Controlando la corrupción ${ }^{1}$, quien llega a demostrar que el PBI de la región Latinoamérica por efectos de este fenómeno podría ser afectado hasta en un 58\% en su resultado. Si se toma en cuenta los aportes de esta investigación, este indicador macroeconómico en el Perú debería estar por el orden de los U\$ 1500 y no tal como nos indican las cifras oficiales. Como se sabe, el PBI percapita, si bien no refleja si un país ha logrado un desarrollo económico equilibrado, pero si es una cifra que señala el avance del escenario económico. Todo país requiere lograr los máximas cifras para este indicador económico como medio para que su población logre mayores niveles de bienestar, pero la corrupción, entre otros conjuntos de facto- res actúan cual mecanismos retardantes para el logro de este objetivo.

No solo el PBI percapita se ve afectado por la corrupción, también lo hace el PBI global, el cual, según estudios realizados por Naciones Unidas, el lavado de dinero, el cual es productos de estos hechos ilegales, llega a ser igual al 5\% de su valor real, cifra que a las claras nos dice que los impactos de este fenómeno va mas allá de los escenarios locales; por ello, no se puede analizar la corrupción evaluando solo presupuestos y variables macro económicas, sociales y políticas de cada país, sino que es necesario que las apreciaciones sean de carácter global, solo así se podrá descubrir sus puntos fuertes y débiles y con ello plantear estrategias para minimizar los impactos de esta amenaza global.

Los analistas argumentan que, si la corrupción se desarrolla en el ámbito gubernamental, los presupuestos públicos son los directamente afectados. Como bien se conoce el Gobierno para lograr sus objetivos sociales cumple el rol de comprador de bienes $y$ ejecutor de obras de infraestructura, es justamente en este proceso que llegan a enquistarse aquellos elementos, que aprovechándose de su poder político ejecutan acciones que al final se traducen en desvió de fondos a cuentas personales. A la luz de este análisis se puede mencionar las cifras trabajadas por la Contraloría General de la Republica (CGR), del gobierno peruano, que a través de su contralor dio a conocer que los actos de la corrupción comprometen en promedio entre un $10 \%$ y $15 \%$ el presupuesto ejecutado y que en 18 meses los corruptos se encargaron de desfalcar al tesoro público cerca de 9 mil millones de soles. Es paradójico que este Organismo de Control denuncie a 1700 de estos funcionarios pero ninguno de ellos

1 Robert Klitgaard, Controlando la corrupción, La Paz, Editorial Quipus, 1990, 210pp 
CARACTERÍSTICAS INGENIERILES DE LA CORRUPCIÓN, EN EL CAMPO ECONÓMICO Y FINANCIERO, Y LA EFICACIA DE LAS ACCIONES DE CONTROL EN LAS ENTIDADES GUBERNAMENTALES EN EL PERÚ

tuvo una sanción definitiva. Cabe precisar que, en promedio las compras del Estado en forma anual llega a los S/ 60 mil millones, pero en el proceso de su ejecución llega a perderse el $15 \%$ del monto señalado, justamente por acción directa de los actos de corrupción.

Si se hace un equivalente de cuanto se hubiera hecho con los montos erosionados por la corrupción, sin duda se podría establecer que la sociedad se priva de importantes proyectos sociales, como la construcción de colegios, hospitales, infraestructura de transporte, que como se como conoce son importantes para elevar sus niveles de bienestar. Debido estos resultados es que el Perú se ubica por debajo de la mitad de la tabla del ranking de Corrupción Global, el cual es trabajado por la ONG Transparencia Internacional. Según los estudios realizados por esta organización global, si un país no es nada corrupto se le asigna un puntaje de 10 y el más corrupto de cero. El Perú no llega alcanzar ni cuatro puntos dentro de este ranking, cifra que en el 2010 lo ubicó en el puesto 120 de 139 países. Sin duda, a la corrupción se le puede calificar como un mal de tipo estructural y de carácter preocupante para los gobiernos.

Cabe precisar con respecto a este punto, a la corrupción, para su neutralización, todos los gobiernos lo han tenido en su agenda de gobierno, por ello, se dieron propuestas de todo tipo, hasta se han conjugado esfuerzos de sociedades civiles, pero a pesar de todas estas acciones, allí sigue este fenómeno pernicioso, generando distorsiones en todos las esferas económicas y sociales del país, tal es así que el estudio realizado por Alfonso Quiroz se llega a establecer que entre 1990 y el año 2000 la corrupción se encargó de desfalcar al Estado US\$ 14 mil millones, casi el $50 \%$ del valor de las exportaciones, de los cuales, vía cuentas encriptadas fueron a parar a importantes paraísos financieros. Cuando los presupuestos públicos son mal usados y los que se encargan de desequilibrarlos intencionalmente desvían fondos a cuentas particulares, lo que realmente están haciendo es ejercer actos corruptos en contra de los ciudadanos y empresas. que como se conoce, son los sujetos que sirven de fuente de financiamiento de los presupuestos públicos, por el pago de sus impuestos .

Como se señalo entre 1990 y el 2000 el costo de la corrupción fue de 14 mil millones de dólares. Aquí surge una pregunta. ¿Cuántas acciones sociales en promedio se hubieran ejecutado con ese presupuesto? : aquí una lista de ellos.

$\checkmark$ Entregar a cada familia peruana 3,000 dólares.

$\checkmark$ Construir 16,600 grandes centros educativos con primaria y secundaria completa y totalmente equipados; o

$\checkmark$ Pagar pensiones de aproximadamente 1,000 soles mensuales a medio millón de jubilados durante 7 años; o

$\checkmark$ Financiar durante 88 años el Seguro Integral de Salud; o

$\checkmark$ Construir 200 mil departamentos del programa Mi vivienda

Realmente, quien perdió por los efectos de la corrupción no fue el Estado, sino la población en general, entre ellos aquellos que no cuentan con los recursos económicos suficientes para afrontar gastos que eleven su nivel de vida, nos estamos refiriendo específicamente a la población menos favorecida de una sociedad.

La corrupción utiliza los métodos más sofisticados que pueda existir en el mercado o que pueda otorgar la imaginación para cubrir sus hechos delictuosos. Sin duda los análisis económicos y financieros deben es- 
tar presentes en sus actos delictuosos permitiéndoles así tomar la mejor decisión. Como se conoce, la potencia cognositiva por si sola no da el valor agregado para corregir los problemas de la corrupción, esta tiene que estar acompañada por la buena conducta y elevados valores del profesional o sujeto que por diversos motivos le toca ejercer el poder político o económico. No es novedad que los métodos que utiliza para sus fines particulares, cada día se fortalecen en mayor grado en su sofistificacion, estas acciones de contrainteligencia le ha permitido su avance y desarrollo y además ha neutralizado las acciones de control de las entidades gubernamentales. Las teorías financieras, los modelos económicos, los estudios tributarios, entre otras disciplinas científicas no son utilizadas como es normal, para dar solución a problemas Privados o Gubernamentales, todo lo contrario, son disciplinas que sin duda están presente para obtener el mejor Valor Actual Neto(VAN) o Tasa Interna de Retorno (TIR), tal como si fuera un proyecto de inversión o plan de negocios. Es así como viene actuando la corrupción globalizada.

\section{CONCLUSIONES}

1. Los gobiernos siempre han agendado la corrupción como tema importante para la gestión de sus políticas públicas , pero a pesar de estos esfuerzos para su neutralización o eliminación, este fenómeno pernicioso sigue generando graves distorsiones en la sociedad

2. La corrupción no solo es un fenómeno local, sino que tan igual como la economía y las finanzas, se ha globalizado y con ello sus efectos traspasan las fronteras de los países hasta convertirse en una amenaza global.
3. La corrupción utiliza circuitos financieros interconectados por los medios tecnológicos que les permite desviar recursos presupuestales a plazas extranjeras, evidenciándose así las deficiencias de los organismo de control y otras entidades públicas de este mismo tipo, que como se sabe, tienen por función corregir estos hechos ilegales

4. Los desvíos de recursos financieros por parte de la corrupción ha conllevado que la sociedad pierda bienestar social, el cual se sustenta por las obras de infraestructura económica y social que se hubiera podido ejecutar con los recursos financieros que fue malversado por los actores directos de este fenómeno delictivo.

5. Los actores de la corrupción aprovechan las vulnerabilidades de los marcos normativos, por ello estos actos ilegales siguen fortaleciéndose especialmente en los sectores donde se ejecutan importantes recursos financieros.

\section{REFERENCIAS BIBLIOGRÁFICAS}

1. KLITGAARD: Controlando la corrupción. La Paz, Editorial Quipus. 1990. 210 $\mathrm{pp}$

2. QUIROZ, Alfonso. Corrupt Circles. A history of unbound graft in Peru. Washington: Woodrow Wilson Center Press. 2008. p

3. TRASPARENCIA INTERNACIONAL: Índice de la corrupción: 2010 -2011 .

4. TRANSPARENCIA INTERNACIONAL: Índice de Soborno : 2010 -2011

5. APOYO Y AOSIADOS : Encuestas Nacional de Corrupción:_lima Perú 